\title{
The impact of cow keeping technologies on milk production of cows and their protection against midges in summer
}

\author{
O. A. Fiodorova, E. I. Sivkova, M. I. Serkova \\ ORCHID ID: 0000-0002-0589-2373, 0000-0002-2837-7235, 0000-0002-0373-7046
All-Russian Scientific Research Institute of Veterinary Entomology and Arachnology - Branch of Federal State Institution Federal Research Centre Tyumen Scientific Centre of Siberian Branch of Russian Academy of Sciences, Russia

*Corresponding author E-mail: fiodorova-olia@mail.ru

Received: 08.06.2020. Accepted: 08.07.2020

\begin{abstract}
Data are presented on the average daily milk yield of cows during the mass abundance of horseflies, mosquitoes and midges depending on the technology of keeping animals in the Tyumen region. Keeping the cows during this period without grazing on the walking grounds at the farm is one of the methods of preserving their milk productivity. During the period of mass flight of gnats, the milk productivity of cattle grazing in forest pastures is significantly reduced. Loss of milk during this period is $13.68 \%$, while the longer the harmful effects of the vulture, the more significant these losses.
\end{abstract}

Keywords: Dependence; Milk productivity; Abundance; Midge; Content technology

\section{Introduction}

Cattle breeding is an important part of the agricultural sector in the Russian Federation. Agriculture has a huge impact on the life of our country as the food security of the state directly depends on it, especially in difficult conditions of the current political situation. At the present time in the conditions of food import embargo and dynamic phase-out of imports, providing the population with food becomes a key priority. Successful development of cattle breeding is an urgent task, the solution of which largely depends on preventing animal productivity losses caused by parasitizing blood-sucking dipterous insects (horseflies, mosquitoes, biting flies and midges).

In dairy cattle breeding two animal keeping systems are used: stall housing with zero grazing (no pasture) and stall housing combined with open grazing and two methods of keeping: tie-stall and free-stall (Dolgova, 2012; Rubina, 2017; Nikishina, 2018). In natural conditions of the south of the Tyumen region, it was found that the milk yield of cows in different pastures, depending on the abundance of biting insects, goes down by $20-45 \%$, and animal weight growth decreases by $25-40 \%$. As a result, during the period of massive swarming of midges, the farms in the region annually lose about 100-200 tons of milk from every thousand of cows and about 11-25 tons of animal weight gain from every thousand of young cattle. The damage caused by insects of a "midge" group consists of a number of factors: painfulness of bites; blood loss; intoxication caused by the mosquito's saliva during bloodsucking; inflammatory processes in bite sites; reduction of body resistance; stressed condition and disturbed process of normal grazing. Besides, blood-sucking dipterous insects transfer causative agents of such diseases as onchocercosis, setariosis, parafilariosis, anaplasmosis, bluetongue virus, Schmallenberg disease, anthrax and others.

At the present time many farms in the south of the Tyumen region are choosing zero grazing keeping system in the summer period. Particularly, such approach is practiced by the farms that keep highly productive imported dairy cows. During the summer period, these animals are kept on the farm in the barns and farmland enclosures.

It is known that if open grazing system is used during the period of massive swarming of midges (June-July) then productivity of animals decreases (Fiodorova, 2018). For example, in the south of the Tyumen region in the subzone of small-leaved forests of the forest zone (Tyumen district), according to data provided by S.D. Pavlov (1962), as a result of massive attacks of midges (horseflies and mosquitoes mainly) in the year of 1961, daily milk yield of each cow dropped by 1.1-2.25 liters, daily milk yield of highly productive cows decreased by more than 3.5 liters, that making 11-19\% and more; in the forest-steppe zone (Ishimsky district), according to data provided by V.I. Bukshtynov (1964), milk productivity of cows goes down by $14.4 \%$ and weight gain of young animals is $25 \%$ less. Massive swarms of bloodsucking dipterans can be observed in the pastures during the grazing of animals (Pavlov et al., 2018). For example, the number of horseflies in cattle grazing areas is 3-12 times higher than in other areas (Pavlova, 1968; Soboleva, 1981). Besides, the larger is the herd population, the greater is the number of horseflies attacking it (Balashov et al, 1985; Konstantinov, 1990).

The goal of this research is to study changes in milk productivity of cows affected by midge attacks with consideration of different types of animal housing. To achieve this goal, the following tasks were set: 1) to study the seasonal dynamics of the number of horseflies, mosquitoes and midges in the pastures and farms, and 2) to analyze the changes in milk production of cows before and during the time of the midge season comparing different animal housing systems. 


\section{Materials and Methods}

The research was conducted in 2018 in the cattle pastures belonging to 000 "Chaika" (village of Kievo) of the Yalutorovsky district in the Tyumen Region (subzone of deciduous aspen and birch forests of the forest zone). The farm provided housing for 200 cows in the period from June 1 to June 25; from June 26 to July 25 the number of cows was 205 . The reported data of the farm on average daily milk yield per a forage-feed cow was used to assess milk productivity. In June and until July 6 the animals of this farm were milked and kept indoors during the night time, and during the day they were in an enclosure adjacent to the cattle housing building. Starting from July 7 the cows were taken to the pasture where they were grazing from 9-10 a.m. and until 4-5 p.m., and starting from July 9 and up to July 23 before driving off to pasture they were treated according to Methodological instructive regulations... (2003), by $0.001 \%$ (according to Active Ingredient) water emulsion of Delcid (4\% e.c. deltamethrin, IRC (Innovation and Research Center) "Agrovetzashchita") by the method of medium-volume spraying with the use of universal horizontal wholetube boom sprayer (UHWBS) designed by All-Russian Research Institute of Veterinary Entomology and Arachnology- Branch of Tyumen Scientific Center, SB RAS (the Siberian Branch of Russian Academy of Sciences)(Gavrichkin et al., 2018). The treatments were performed once every three days; 6 treatments were done in total.

The number of blood-sucking dipterous insects was studied in two pastures. The first pasture (experimental) was located behind the farm and served as a grazing place for cows of $\mathrm{OOO}$ "Chaika" from July 7 to the end of the summer season. The second pasture (control) was at a distance about 3-5 km from the first; about 100 privately-owned cows and calves from the village of Kievo grazed there during the entire summer season.

The number of blood-sucking dipterous insects was counted once every 5-7 days. Horseflies were counted with the use of spherical traps during a day (Pavlov, Pavlova, 1986), mosquitoes and midges were counted by the use of an entomological net "sweep around"; the average data of 10 strokes from 10 repeated ones during 18-20 hours was taken into consideration (Detinova et al., 1978). To assess the influence of treatment sprayed on cattle affecting the number of midges in the pasture, comparative accountings of the numbers were carried out in both pastures three times before the treatment period and three times during it. The entomological efficiency of the treatments (protective action coefficient, PAC) was calculated according to the Methodological instructions... (1982) by the following formula:

$$
P A C=100-\frac{A \times B_{1}}{B \times A_{1}} \times 100,
$$

where $\mathrm{A}$ and $\mathrm{A} 1$ are the numbers of midges counted in the experimental pasture during the treatment period and before it; $\mathrm{B}$ and $\mathrm{B} 1$ - the corresponding data taken in the control pasture.

Besides, accountings of horseflies, mosquitoes and midges were conducted simultaneously by going around 10-15 cows and counting insects sitting on them; then calculation of the abundance index was done. (Breev, 1950).

As control data for comparing milk productivity of cows with different housing systems, we used data on the productivity of cows of the same herd of $\mathrm{OOO}$ "Chaika" received for the season of 2017, during which the animals grazed in the pastures daily. With that, the approximate dates of massive minge swarming were determined in accordance with the results of our research of this season, carried out in the Tyumen region located next to the same subzone of small-leaved aspen-birch forests of the forest zone.

To compare the index harmfulness of different midge types, conventional units of harmfulness were applied according to which an attack of one medium-sized horsefly such as Hybomitra bimaculata Macq., Tabanus bromius L., Atylotus fulvus Mg. is equal to an attack of 0.46 specimens of large horseflies ( $T$. bovinus L., $H$. tarandina L.), 3.42 specimens of dun flies (Haematopota type) and deer flies (Chrysops type), 29.3 specimens of mosquitoes and 70.7 specimens of midges. With that, conventional coefficients of conversion of natural abundance numbers into conventional units of harmful abundance respectively equal to $1 ; 2.17 ; 0.29 ; 0.034$ and 0.014 (Pavlova, 1997).

\section{Results}

Data on the abundance of midges counted in conventional units in the pasture and data on milk productivity of cows during the experimental period in 2018 are presented in Figure 1, according to which swarming of the researched midge types began in the first decade of June. Until mid-June, the abundance remained at a low level, that is, it was below the economic threshold of harmfulness. Starting from mid-June, the abundance numbers began to increase, reaching a maximum by the end of the month. A short cold spell in the beginning of July caused a decrease in the number of midges mainly due to a sharp decrease in the number of horseflies. By the end of the first decade, due to a rise in temperature, the midge abundance increased again and remained at a considerably high level until the middle of the third decade of July. Thus, massive swarming of midges was observed from mid-June until the middle of the third decade of July.

As one can see from the presented figure, with cattle grazing during the day in the enclosure next to the cattle housing building, both in the period before the beginning of massive swarming of midges (from June 1 to 15 ) and during it (from June 16 to July 6 ), the curve line of an average daily milk yield per one forage-fed cow remained almost at the same level. With the beginning of animal grazing in the pasture during the ongoing massive swarming of midges from July 7 to July 25 , milk productivity of cows began to decline rapidly.

Statistically processed data presented in Table 1 show that when the cows grazed in the enclosure adjacent to the farm during the daytime, the average daily milk yield before the beginning of massive swarming of midges (16.233 I) and during it (16.126 I) did not have significant differences (at $\mathrm{P}=95 \%$ ), although there was a slight decrease by 0.107 liters $(0.66 \%)$. When the cows started to graze in the pasture in the period from July 7 to 25 , the average daily milk yield decreased by 1,203 liters (7.46\%), amounting to an average daily milk yield of 14.923 liters. With that, milk yields of cows grazing in the enclosure and of those ones grazing in the pasture had significant differences, with a confidence level of $99.9 \%$. For the entire period of massive swarming of midges, milk yield per one forage-fed cow averaged 15.555 liters per day, that is, compared with the period before the beginning massive swarming of midges, it decreased by 0.678 liters or $4.18 \%$.

A study of the midge abundance in the enclosure showed that in the daytime the animals were not attacked by these insects before the beginning of massive swarming of midges. During the period of massive swarming of midges from June 16 to July 6 , the abundance number of these insects sitting on the cows in the enclosure was extremely low. 


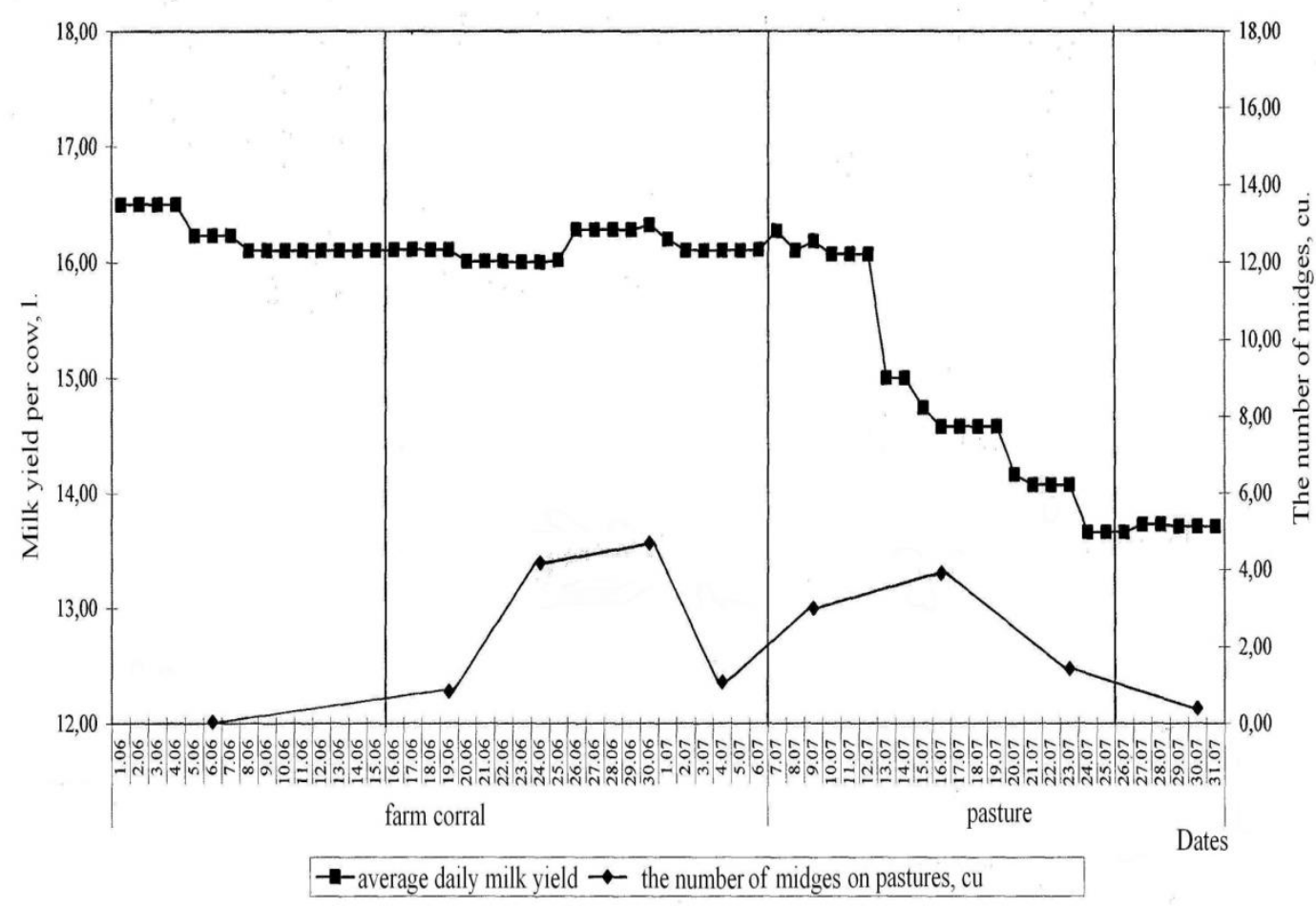

Figure 1. Milk productivity of cows during the flight of the midges with non-grazing and grazing content (2018 yr).

Table 1. The average daily milk yield of cows in the experiment and control, L.

\section{Research Periods}

1. Non-grazing content until the mass flight of the midge from June 1 to June 15

2. Non-grazing content in the first half of the mass flight of insects from June 16 to July 6

3. Mainetance using pastures and periodic treatment of cows with delcid in the second half of the mass flight of insects from June 7 to 25

During the entire period of the mass flight of the midge from June 16 to July 25

$\begin{array}{cc}\begin{array}{c}\text { Test-subject herd } \\ (\mathbf{2 0 1 8} \text { yr.) }\end{array} & \begin{array}{c}\text { Control herd } \\ (\mathbf{2 0 1 7} \text { yr. })\end{array} \\ 16,233 \pm 0,045 & 17,112 \pm 0,047 \\ 16,126 \pm 0,023 & 15,978 \pm 0,135 \\ 14,923 \pm 0,211 & 13,437 \pm 0,128 \\ & \\ 15,555 \pm 0,138 & 14,771 \pm 0,233\end{array}$

Test-subject herd

(2018 yr.)

$15,555 \pm 0,138$

$$
\begin{gathered}
\begin{array}{c}
\text { Control herd } \\
(\mathbf{2 0 1 7} \text { yr. })
\end{array} \\
17,112 \pm 0,047 \\
15,978 \pm 0,135 \\
13,437 \pm 0,128 \\
14,771 \pm 0,233
\end{gathered}
$$

Note: the control herd during all periods of research had kept using pastures without the use of protective treatments against midges.

For example, simultaneous accountings of the midge abundance for 10-15 animals showed a maximum of 3-5 midges, 1 mosquito and 1-2 horseflies, therefore, most animals were not attacked at all, even by single specimens. Almost total absence of midge specimens on the animals during the day in summer enclosures can be apparently explained by the smell of animal urine coming from the soil and piles of animal manure which emit ammonia. The repellent (scaring off) effect of ammonia on horseflies is mentioned by R.P. Pavlova et al. (1976).

When the cows grazed in the pasture from July 7 to 25 , the abundance number of midges calculated in conventional units changed during one attack on a cow simultaneously in the herd from 1.41c.u. to $3.91 \mathrm{cu}$, with an economic threshold of $0.8 \mathrm{cu}$ (Pavlova, 1997). Midge attacks on cows caused a drop in their milk productivity during that period.

Spraying the cattle with delcid before driving it off to the pasture, as we have previously determined (Pavlov et al., 2002), provides a protective effect against the midge at the level of $84 \%$ for more than a day. In the following two days, the intensity of attacks of bloodsucking insects increases and approaches the index in the control pasture. It was observed that besides providing direct protection of animals, delcid having an insecticide effect caused a decrease in the total number of midge abundance. For example, a comparison of the abundance number of insects in the experimental and control pastures before the animal treatments and during that period showed that in the experimental pasture the number of horseflies decreased by 51.14 as a result of animal treatments, and the number of midges went down by $41.66 \%$ (Table 2 ). 
Table 2. Entomological efficacy of protecting cattle from gnats (in the numerator - experiment, in the denominator - control).

\begin{tabular}{cccccccccc}
\hline Insects & \multicolumn{3}{c}{$\begin{array}{c}\text { Number before } \\
\text { processing }\end{array}$} & $\begin{array}{c}\text { Insects } \\
\text { collected }\end{array}$ & \multicolumn{2}{c}{$\begin{array}{c}\text { Number during } \\
\text { processing }\end{array}$} & $\begin{array}{c}\text { Insects } \\
\text { collected }\end{array}$ & $\begin{array}{c}\text { Entomological } \\
\text { Efficiency, \% }\end{array}$ \\
& 24.06 & 30.06 & 4.07 & & 9.07 & 16.07 & 23.07 & & \\
Horsefly & 762 & 585 & 31 & 1378 & 555 & 792 & 228 & 1575 & 51,14 \\
& 642 & 1194 & 21 & 1857 & 830 & 2630 & 884 & 4344 & 41,66 \\
Midges & 49,7 & 114,6 & 65,6 & 259,9 & 31,8 & 21,5 & 27,6 & 80,9 & \\
& 32,4 & 97,5 & 99,9 & 229,8 & 63,1 & 45,0 & 14,5 & 122,6 & \\
\hline
\end{tabular}

Thus, despite an almost twofold decrease in the number of bloodsucking dipterous insects in the pasture, the natural losses in milk productivity of cows amounted to 1.203 litres or $7.46 \%$, which indicates the need for more frequent treatments during the period of a massive swarming of midges. The appearance of the midge in the control season of 2017 was noted at the end of May, but until mid-June, due to a cold spell, the abundance number was below the economic threshold. Massive swarming of midges began on June 15 and continued until July 30. Peak abundance numbers were recorded at the end of June. Data on the abundance number of midges in the pasture and milk productivity of cows for the year 2017 are given in Figure 2, indicating that when the cows were grazing in the pasture when the period of massive swarming of midges began, a decrease in average daily milk yields was observed and it continued until the end of this period. According to the data presented in Table 1, during that season before the beginning of massive midge swarming in the period from June 1 to June 15, the average daily milk yield was 17.112 liters, and during the period of massive midge swarming from June 16 to July 6 - it was 15.978 liters, thus, it decreased by 1.134 liters (6.63\%). During the ongoing massive midge swarming from July 7 to July 25, milk yield amounted to an average of 13.437 liters, that is, showing a further decrease by 2.541 liters (15.9\%). Based on these data, one can see that with an increase in the duration of the harmful effects of midges, the losses of milk productivity increase. For the entire period of massive midge swarming from June 16 to July 25 , 2017, the average daily milk yield per a forage-fed cow amounted to 14.771 liters, that is, compared with the period before the beginning of massive midge swarming (from June 1 to 15), it decreased by 2.341 liters or by $13.68 \%$.

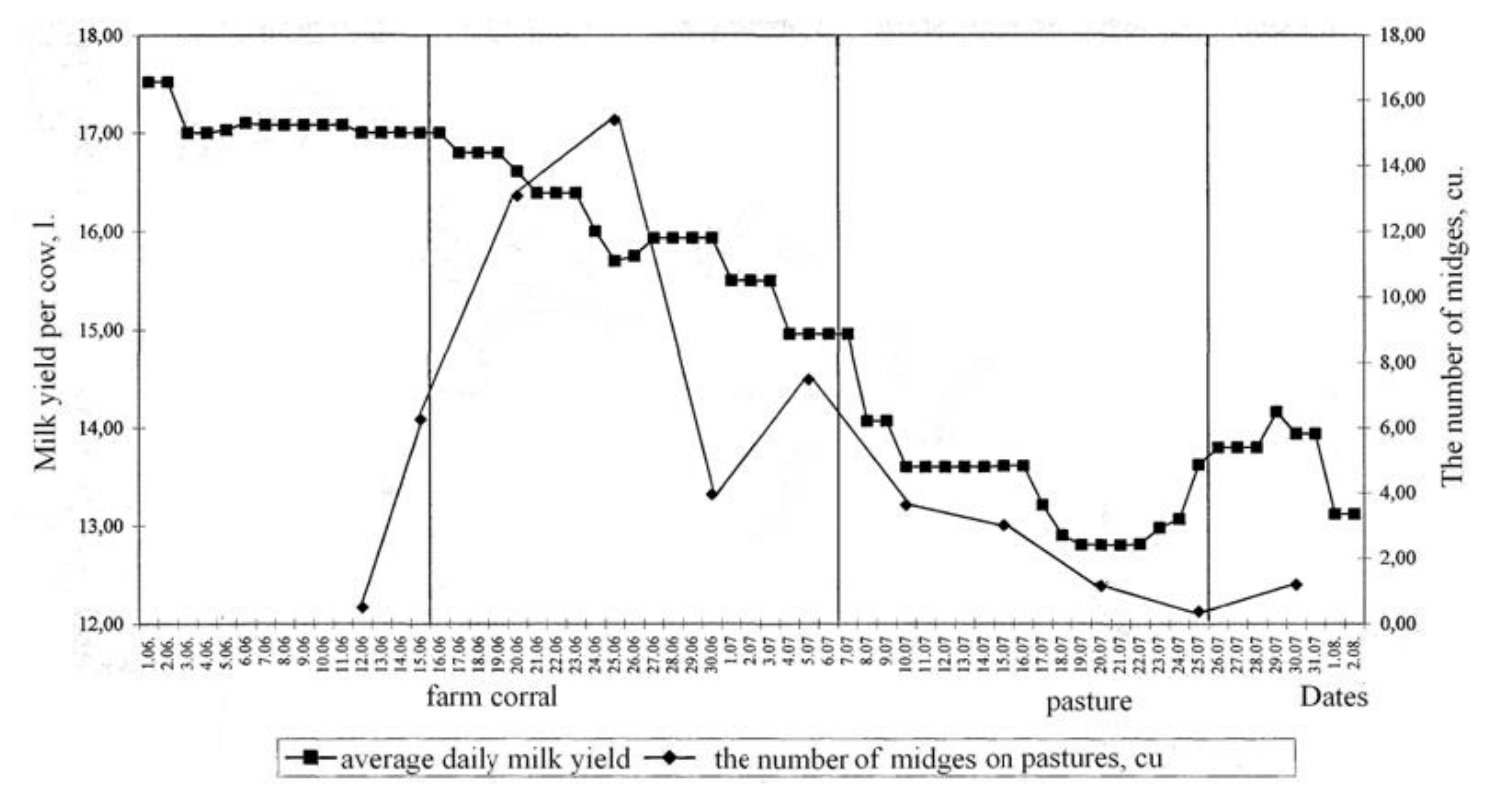

Figure 2. Milk productivity of cows during the flight of the midges with grazing content (2017 yr).

Based on the results of this research, additional calculations of changes in the productivity of experimental cows were made, adjusted for the productivity of animals that grazed in the control pasture during the whole summer season. For this, according to the Methodological instructions (1982), the following equations were used:

$$
\mathrm{DP}=\mathrm{A} 2-\mathrm{A} 1 \frac{\mathrm{B} 2}{\mathrm{~B} 1} \text { (I) } \quad \text { n } \quad \mathrm{E}=100 \frac{\mathrm{A} 2 \mathrm{~B} 1}{\mathrm{~A} 1 \mathrm{~B} 2}-100(\%) \text {, }
$$

where $A 1$ and $A 2$ are the productivity of the experimental animals, respectively, before the experiment and during the experiment; $\mathrm{B} 1$ and $\mathrm{B} 2$ are the productivity of control animals, respectively, before the experiment and during the experiment;

$\mathrm{DP}$ and $\mathrm{E}$ - respectively, added production and relative change (increase) in animal productivity, expressed in a percentage.

According to these calculations, in the first period of massive swarming of midges from June 16 to July 6 , there is an index of saved milk product amounting to 0.969 litres or $6.39 \%$ in the average daily milk yield of experimental cows kept according to a zero grazing system in comparison with the cows grazing in the control pasture:

$$
15.978
$$

$\mathrm{DP}=16,126-16,233 \frac{17.978}{17.112}=0,969 \mathrm{l}$; 


$E=100 \frac{16,126 \times 17,112}{16,233 \times 15,978}-100=6,39 \%$.

This meaning that as a result of zero grazing of animals in the first period of massive swarming of midges, milk yields of 200 cows gave additionally saved milk product amounting to more than 4 tons of milk in the period of 21 days.

In the second period of massive swarming of insects of a "midge" group, when the animals were driven off to the adjacent pastures during the daytime and periodically (once every 3 days) received anti-midge protection treatment, from July 7 to July 25 there was still an index of saved milk product amounting to 2.176 litres or $17,07 \%$ in the average daily milk yield of experimental cows in comparison with the cows grazing in the control pasture:

$D P=14,923-16,233 \frac{13.437}{17.112}=2,176 \mathrm{I} ;$
$E=100 \frac{14,923 \times 17,112}{16,233 \times 14,437}-100=17,07 \%$.

This meaning that in the second period of massive swarming of insects, when the experimental cows received treatment against the midges and were kept in the pasture during the daytime, milk yields of the same 200 cows gave additionally saved milk product amounting to more than 8 tons of milk in the period of 19 days. A significant part of additionally saved milk productivity of the experimental cows should be attributed to the fact that they received insecticide treatment, as a result of which, for example, the number of horseflies in the experimental pasture was reduced by $51.1 \%$ compared with the control one and the number of mosquitoes went down by $41.7 \%$.

In general, during the entire period of massive swarming of midges (40 days), average daily milk yields of the experimental cows who first had zero grazing system and then received treatment before being driven off to the pasture, showed an index of saved milk product amounting to 1.543 I or $11.01 \%$ compared to cows in the control pasture:

$D P=15,555-16,233 \frac{14.771}{17.112}=1,543$ l;
$E=100 \frac{15,555 \times 17,112}{16,233 \times 14,771}-100=11,01 \%$.

Therefore, during the entire period of massive swarming of bloodsucking dipterous insects, the taken steps contributed to saving milk product that amounted to 12 tons of milk during 40 days in the yields of the same 200 experimental cows compared to those in the control pasture.

\section{Conclusion}

In the south of the Tyumen region, in the subzone of aspen-birch forests of the forest zone during the period of massive swarming of midges, milk productivity of cattle grazing in forest pastures goes down significantly. Losses of milk during this period make $13.68 \%$, with that, the longer is the duration of harmful effects of the midges, the more significant are the losses. Zero pasture system of keeping cows with the use of farmland enclosures for grazing during the daytime where the midges practically don't disturb the animals is one of the rational methods for keeping their milk productivity. If pasture grazing is used, systematic spraying of animals with insecticides belonging to the group of synthetic pyrethroids ensures a reliable protection from the midges.

The article was prepared with the financial support of the Basic Research Program of the Russian Academy of Sciences, "Study of the effectiveness of new antiparasitic drugs".

\section{References}

Balashov Yu.S., (1985). Scatter and abundance of horseflies of the genus Hybomitra Enderlain (Tabanidae) around cattle herds/Balashov Yu.S., Veselkin A.G., Konstantinov S.A., Ulyanov K.N. // Entomol. review. 64 (1) 74-78.

Bukshtynov V.I. (1964). Cost and cost-effectiveness of measures to protect cattle from midges // Probl. vet. Sanitation: Tr. VNIIVS. 24: 326-331.

Breev K.A. (1950). About the behavior of blood-sucking dipterans and gadfly during their attack on the reindeer and the responses of the deer. Communication 1. The behavior of blood-sucking dipterans and gadflies when they attack a reindeer // Parasitol. Sat/Zool. Inst. USSR Academy of Sciences. 12: 167-198.

Gavrichkin A.A. (2018) The main technical parameters of a universal installation for spraying animals/Gavrichkin A.A. Pavlov S.D., Fedorova O.A., Khlyzova T.A., Sivkova E.I. // Tauride Journal of Agricultural Science. 94-101. DOI 10.25637/TVAN2018.01.08 Detinova T.S. (1978). Rasnitsyn S.P., Markovich N.Ya. et al. Unification of methods for accounting the number of blood-sucking diptera insects // Honey. parasitol. 5: 84-92.

Dolgova E.A. (2012) The main factors for the effective management of dairy cattle breeding // Innovations and Investments. 1: $125-128$.

Konstantinov S.A.(1990) Features of the attack of horseflies and mosquitoes on cattle in the pastures of the north-west of the RSFSR: Abstract. dis ... cand. biol. sciences. p. 25. 
Pavlov. S.D. (1982) Guidelines for the study of the effectiveness of repellents and insecticides in veterinary medicine VASKHNIL. 13. Guidelines for the use of "Delcida" against ectoparasites of animals (in the order of production tests in 2003-2004)/Approved. Head of the Veterinary Department of the Administration of the Tyumen Region. - 2003. p. 6.

Nikishina A.V. (2018) Milk productivity of cows depending on the influence of various factors // Experimental and theoretical studies in modern science: Coll., Based on materials from the XVth International Scientific and Practical Conference No. 6 (15). Novosibirsk: SibAK, $50-56$.

Pavlov S.D. (1962) The economic effect of protecting animals from midges // Probl. vet. Sanitation: Tr. VNIIVS. 20: $172-178$.

Pavlov S.D.(1986). Methodological recommendations on the use of traps for collecting, counting the abundance and extermination of horseflies on pastures/ Pavlov S.D., Pavlova R.P. /VASKHNIL. Veterinary Department. - Moskow. 18.

Pavlov S.D. (2002) Industrial approbation of delcide to protect cattle from nests in grazing conditions/Pavlov S.D., Pavlova R.P., Rzhanikov S.N., Krieger A.L., Mavlyutov S.M. // Probl. Entomology and arachnology: Sat. scientific tr/VNIIVEA. 44: $129-134$.

Pavlova R.P. (1968) About the number of horseflies in cattle grazing // Probl. vet. Sanitation: Tr. VNIIVS. 31: 18-22.

Pavlova R. P. (1977) Comparative harmfulness and economic thresholds for harmfulness of blood-sucking diptera insects for dairy cows // Probl. Entomology and arachnology: Sat. scientific tr/VNIIVEA. 38: $112-130$.

Pavlova R.P. (1976) Test results of some attractants in horse traps/Pavlova R.P., Pavlov S.D., Popov T.P. // Vopr. vet. arachno entomology: Scientific-technical. bull. 8: 59-67.

Rubina M.V. (2017) The effectiveness of milk production in different systems of keeping cows/Actual problems of the intensive development of animal husbandry. 122-128.

Soboleva R.G. ( 1981) Fauna and biology of horseflies (Diptera, Tabanidae) of the Ussuriisky Reserve named after V.L. Komarova, Primorsky Territory // New information about insects of the Far East. - Vladivostok. 101-111.

Gavrichkin A.A. (2018) The ethology of blood-sucking midges (Diptera: Ceratopogonidae) while attacking animals/Gavrichkin A.A., Fiodorova O.A., Sivkova E.I., Siben A.N. // International Journal of Pharmaceutical Research. 10 (10) 305-309 https://doi.org/10.31838/ijpr/2018.10.027

Pavlov S.D. (2018) Stydy of efficiency two preparation forms of repellant alezan/Pavlov S.D., Fiodorova O.A., Khlyzova T.A., Sivkova E.I. // Journal of Pharmaceutical Sciences and Research. 10(7) 1707-1709.

Fiodorova O.A. (2018) The physiological age of female blood-sucking midges (Diptera: Ceratopogonidae) // Biosystems Diversity 26 (3): 179-182 https://doi.org/10.15421/011827.

\section{Citation:}

Fiodorova, O.A., Sivkova, E.I., Serkova, M.I. (2020). The impact of cow keeping technologies on milk production of cows and their protection against midges in summer. Ukrainian Journal of Ecology, 10(3), 6-11. 